\title{
A multi-objective train-scheduling optimization model considering locomotive assignment and segment emission constraints for energy saving
}

\author{
Hui Hu $\cdot$ Keping Li $\cdot$ Xiaoming Xu
}

Received: 14 September 2012/Revised: 12 March 2013/Accepted: 22 March 2013/Published online: 6 June 2013

(C) The Author(s) 2013. This article is published with open access at Springerlink.com

\begin{abstract}
Energy saving and emission reduction for railway systems should not only be studied from a technical perspective but should also be focused on management and economics. On the basis of relevant trainscheduling models for train operation management, in this paper we introduce an extended multi-objective trainscheduling optimization model considering locomotive assignment and segment emission constraints for energy saving. The objective of setting up this model is to reduce the energy and emission cost as well as total passengertime. The decision variables include continuous variables such as train arrival and departure time, and binary variables such as locomotive assignment and segment occupancy. The constraints are concerned with train movement, trip time, headway, and segment emission, etc. To obtain a non-dominated satisfactory solution on these objectives, a fuzzy multi-objective optimization algorithm is employed to solve the model. Finally, a numerical example is performed and used to compare the proposed model with the existing model. The results show that the proposed model can reduce the energy consumption, meet exhausts emission demands effectively by optimal locomotive assignment, and its solution methodology is effective.
\end{abstract}

Keywords Energy saving - Emission reduction - Train scheduling · Multi-objective optimization - Locomotive assignment

\footnotetext{
$\mathrm{H} . \mathrm{Hu} \cdot \mathrm{K} . \mathrm{Li} \cdot \mathrm{X} . \mathrm{Xu}$

State Key Laboratory of Rail Traffic Control and Safety, Beijing Jiaotong University, Beijing 100044, China

H. Hu $(\bowtie)$

School of Economics and Management, East China Jiaotong

University, Nanchang 330013, China

e-mail: hh24895@163.com
}

\section{Introduction}

Along with the growing agreement on the concept of sustainable transportation, energy saving and emission reduction in railway system are receiving more and more attention. Compared to other transport modes, railway system has many advantages such as lower fuel consumption and exhausts emission for freight and passenger movements. Hence, rail transport will inevitably play an important role in meeting global transportation demands.

From a systematic point of view, energy consumption and exhausts emission in railway systems should be considered in rail transport planning so that energy reservation and emission reduction can be effectively attained in the different planning processes. The railway transport planning is a highly complex process which contains passenger demand analysis, line planning, train scheduling, rolling stock planning, crew planning, and crew rostering $[1,2]$.

In this paper, we place the focus of energy saving and emission reduction in railway systems on the train scheduling. First, an improved multi-objective train-scheduling optimization model considering segment emission constraint for energy saving and emission reduction is put forward on the basis of relevant models by assigning different groups of locomotives and carriages. Then, we employ a fuzzy multi-objective optimization approach to obtain the non-dominated solutions. Finally, a numerical example is presented and compared to illustrate the efficiency of the proposed model and solution methodology.

\section{Literature review}

As one of the most challenging problems in railway planning, train scheduling is to determine the time all trains 
arrive and depart each station on an entire line or network, i.e., the train timetable. There are two methods used to have a practically reasonable timetable. One is through a trial and error process using a preliminary train diagram. The other is computer-based, such as mathematical programing [3, 4], simulation [5, 6], and expert systems [7, 8]. As the improvement of computer speed, mathematical programing first applied by Amit and Goldfard [9] has become the most popular approach which has been used for optimizing different models such as trip time [10], delay time [11], reliability [12], deviation from a preferred time table [13, 14], operation cost [15], and so on. Cordeau et al. [16] have made a good survey about the single-objective optimization methods.

Train scheduling is inherently a multi-objective decision problem since an effective timetable should trade off the benefit of railway companies against the benefit of passengers. On one hand, railway companies prefer to minimize the operation cost, which has a conflict with the benefit of passengers who need a shorter trip time. As a result, more and more studies have been shifted to the tradeoff between operation cost and trip time by formulating multi-objective optimization models $[1,3,15]$.

Compared to single-objective approaches, multi-objective approaches are generally proved to be capable of producing better solutions since more relevant factors can be considered as optimization objectives and evaluated in non-commensurable units in different relevant areas.

To realize energy saving in railroads and rail transit systems, the major operations include energy-efficient design of locomotives and motor units [17, 18], effective reduction of resistance to the train movement [19-21], proper maintenance of rolling stock and tracks [22, 23], optimal operation strategy of train movement [24-27], and design of efficient timetables [28-30] etc.

Studies on exhaust emissions reduction in railway systems can be classified into three categories: the specific emission reduction technologies and systems for locomotives and rail-yards [31, 32], the emission estimation models [33-40], and the evaluation of exhaust emissions impacts on human health [41-45]. Here two special studies [1, 15] need to be mentioned, which are related to train-scheduling problem and energy saving. In 2004, Ghoseiri et al. [1] developed a multi-objective optimization model for the passenger train-scheduling problem. Lowering the fuel consumption cost was the measure of satisfaction of the railway company and shortening the total passenger-time was regarded as the passenger satisfaction criterion. In 2012, $\mathrm{Li}$ et al. [15] proposed a green train-scheduling multiobjective optimization model by minimizing the energy and carbon emission cost as well as the total passenger-time.

In this paper, we attempt to make a comprehensive investigation on energy saving and emission reduction combined with train-scheduling problem considering locomotive assignment and segment emission constraints.

\section{Model development}

We try to make some tactical and operational decisions related to train-scheduling: selection of routes; arrival and departure times at each station for all trains; locomotive assignment. Exhausts emission also have been taken into consideration.

\subsection{Notation}

The following indices, parameters, and decision variables are defined and will be used throughout this paper.

\section{Sets}

$I(i \in I) \quad$ Set of train stocks, also referring to trains for simplicity

$L(l \in L) \quad$ Set of locomotives

$S(s \in S) \quad$ Set of stations

$Q(q \in Q) \quad$ Set of segments between two successive stations

$E(e \in E) \quad$ Set of exhausts emissions

$Q_{i} \quad$ Set of segments used by train $i$

$Q_{i s}^{E} \quad$ Set of segments entering into station $s$ used by train $i$

$Q_{i s}^{L} \quad$ Set of segments departing station $s$ used by train $i$

$s_{e q} \quad$ Station via which a train enters segment $q$

$s_{l q} \quad$ Station via which a train leaves segment $q$

\section{Parameters}

$k_{0}^{l}, k_{1}^{l}, k_{2}^{l} \quad$ Resistance coefficients of Davis equation for locomotive $l$

$k_{0}^{i}, k_{1}^{i}, k_{2}^{i} \quad$ Resistance coefficients of Davis equation for the carriage of train stock $i$

$R_{i q} \quad$ Resistance effort on train $i$ traversing segment $q$

$P_{i q} \quad$ Required power for train $i$ traversing segment $q$

$r_{l} \quad$ Amount of fuel consumption per unit power output for locomotive $l$

$N_{i s} \quad$ Number of passengers on train $i$ when it arrives at station $s$

$Y_{i s} \quad$ Number of passengers leaving train $i$ at station

$s$

$Z_{i s} \quad$ Number of passengers boarding train $i$ at station $s$

$T_{i s}^{y} \quad$ Required stopping time for allowing passengers to leave train $i$ at station $s$ 
$T_{i s}^{z} \quad$ Required stopping time for allowing passengers to board train $i$ at station $s$

$M_{i} \quad$ Mass of train stock $i$

$M_{l} \quad$ Mass of locomotive $l$

$N_{l} \quad$ Maximum quantity of locomotive $l$

$g \quad$ Gravity acceleration

$w_{i s} \quad$ The minimum dwell time required for train $i$ when it arrives at station $s$

$h_{q} \quad$ The minimum headway time between two trains on segment $q$

$d_{q} \quad$ Length of segment $q$

$\theta_{q} \quad$ Gradient on segment $q$

$X_{i}^{O_{i}} \quad$ The earliest departure time of train $i$ from its origin station

$X_{i}^{D_{i}} \quad$ The planned arrival time of train $i$ at its destination station

$\eta_{e l} \quad$ Exhaust $e$ emission factor of locomotive $l$

$\xi_{q e} \quad$ Exhaust $e$ emission upper bound on segment $q$

$c \quad$ Unit fuel cost

$\Delta_{e} \quad$ Allowance for exhaust $e$ emission

$\lambda_{e} \quad$ Unit price of exhaust $e$ emission allowance

$\operatorname{big} M \quad$ A large positive number

$u \_v_{i q} \quad$ Upper limit for the average velocity of train $i$ on segment $q$

$l_{-} v_{i q} \quad$ Lower limit for the average velocity of train $i$ on segment $q$

\section{Continuous decision variables}

$v_{i q} \quad$ Average velocity of train $i$ on segment $q$

$t_{i s}^{a} \quad$ Time at which train $i$ arrives at station $s$

$t_{i s}^{d} \quad$ Time at which train $i$ departs at station $s$

$t_{i}^{O_{i}} \quad$ Time at which train $i$ departs from its origin station $O_{i}$

$t_{i}^{D_{i}} \quad$ Time at which train $i$ arrives at its destination station

\section{Binary decision variables}

$L A_{i l}= \begin{cases}1 & \text { if lomotive } l \text { assigned to train } i \\ 0 & \text { otherwise }\end{cases}$

$H_{i q}= \begin{cases}1 & \text { if train } i \text { traverses segment } q \in Q_{i} \\ 0 & \text { otherwise }\end{cases}$

$A_{i j q}=\left\{\begin{array}{cc}1 & \text { if inbound train } i \text { traverses segment } \\ & q \in Q_{i} \cap Q_{j} \text { before inbound train } j \\ 0 & \text { otherwise }\end{array}\right.$

$B_{i j q}=\left\{\begin{array}{cc}1 & \text { if inbound train } i \text { traverses segment } \\ & q \in Q_{i} \cap Q_{j} \text { before outbound train } j \\ 0 & \text { otherwise }\end{array}\right.$

$C_{i j q}=\left\{\begin{array}{cc}1 & \text { if inbound train } i \text { traverses segment } \\ & q \in Q_{i} \cap Q_{j} \text { before outbound train } j \\ 0 & \text { otherwise }\end{array}\right.$
3.2 Energy and emission cost considering locomotive assignment

For each train, the amount of fuel consumption per mass is proportional to the resistance effort and the displacement, where the resistance includes many aspects such as rolling resistance, flange resistance, axle resistance, track resistance, curve resistance, grade resistance, air resistance, and so on. Davis and the American Railway Engineering Association derived a comprehensive train resistance equation, which has been incorporated into many train performance simulators and analytical models [46]. Using Davis equation, the resistance considering the match between locomotive and train stock is defined as

$$
\begin{aligned}
R_{i q}= & \sum_{l} L A_{i l}\left[M_{l}\left(k_{0}^{l}+k_{1}^{l} v_{i q}+k_{2}^{l} v_{i q}^{2}\right)+M_{i}\left(k_{0}^{i}+k_{1}^{i} v_{i q}\right.\right. \\
& \left.\left.+k_{2}^{i} v_{i q}^{2}\right)+g\left(\sin \theta_{q}\right)\right] .
\end{aligned}
$$

For each segment $q \in Q_{i}$, the velocity is determined as $v_{i q}=\frac{d_{q}}{\left(t_{i s_{l q}}^{a}-t_{i s_{e q}}^{d}\right)}$.

The required power can be simplified as $P_{i q}=R_{i q} v_{i q}$. Since the trip time for train $i$ traverses segment $q$ is $d_{q} / v_{i q}$, the fuel consumption is $R_{i q} d_{q} \sum_{i} L A_{i l} r_{l}$. For the whole trip, the fuel consumption for train locomotive $l$ is $E_{i}=\sum_{q \in Q_{i}} R_{i q} d_{q} \sum_{l} L A_{i l} r_{l}$.

Let $c$ denote the cost per unit fuel consumption. Then, the cost on fuel consumption is

$E=\sum_{i} \sum_{q \in Q_{i}} c R_{i q} d_{q} \sum_{l} L A_{i l} r_{i}$.

In addition, if the allowance for emission reduction is considered, the total emission cost is

$F=\sum_{e} \lambda_{e}\left(\sum_{i} \sum_{l} \eta_{e l} E_{i}-\Delta_{e}\right)$

where $\lambda_{e}$ is the unit price for trading the surplus exhaust $e$ emission. If the total exhaust $e$ emission is larger than $\Delta_{e}$, it needs the expenses on buying the extra emission allowances. Otherwise, if the total exhaust $e$ emission is less than $\Delta_{e}$, it means the profit arising from the reduction on exhaust $e$ emission.

\subsection{Total passenger-time}

According to the strategic scheduling plan, each train is scheduled to stop at certain stations to allow passengers to board/leave the train. Arrival at each of these predetermined stations terminates an old sub-journey and starts a new sub-journey. Therefore, the trip of each train is divided into several sub-journeys. The total passenger-time for 
train $i$ transverses the segment $q$ can be formulated as below [1, 15]:

$$
\begin{aligned}
T_{i q}= & \left(N_{i s_{e q}}-Y_{i s_{e q}}+Z_{i s_{e q}}\right)\left(T_{i s_{l q}}^{a}-T_{i s_{e q}}^{a}\right)-\frac{1}{2}\left(N_{i s_{e q}}-Y_{i s_{e q}}\right. \\
& \left.+Z_{i s_{e q}}\right) T_{i s_{e q}}^{y}-\frac{1}{2} Z_{i s_{e q}} T_{i s_{e q}}^{z}
\end{aligned}
$$

So, the total passenger-time for all trains is

$$
T=\sum_{i} \sum_{q \in Q_{i}} T_{i q}
$$

\subsection{Constraints with locomotive assignment and segment emission}

The train-scheduling problem includes the following constraints:

$\sum_{l} L A_{i j}=1$.

Constraint (3) states that a train is only pulled by a locomotive, not considering multi-locomotive traction in this paper.

$\sum_{i} L A_{i l} \leq N_{l}$

Constraint (4) insures that the number of locomotive needed for trains cannot exceed the locomotive maximum capacities.

$t_{i}^{O_{i}} \geq X_{i}^{O_{i}}, t_{i}^{D_{i}} \leq X_{i}^{D_{i}}$.

Constraint (5) points out that each train cannot leave the origin station earlier than its earliest departure time, and it should arrive at the destination station before the scheduled time.

$\sum_{q \in Q_{i s}^{E}} H_{i q}=\sum_{q \in Q_{i s}^{L}} H_{i q}=1$.

Constraint (6) assures that each train should first choose only one segment to come into station $s$, and then one segment to leave the station $s$.

$\sum_{q \in Q_{i s}^{E}} t_{i s}^{d} H_{i q}=\sum_{q \in Q_{i s}^{L}} t_{i s}^{a} H_{i q}+t_{i s}^{y}+t_{i s}^{z}$.

Constraint (7) describes the formulation of arrival time, departure time, and dwell time of each train in station $s$.

$\frac{d_{q}}{u_{-} v_{i q}} \leq t_{i s_{e q}}^{a}-t_{i s_{l q}}^{d} \leq \frac{d_{q}}{l_{-} v_{i q}}$.

Constraint (8) insures that each train's velocity is between the upper limit velocity and the lower limit velocity on segment $q$.

$\sum_{i} \sum_{l} R_{i q} d_{q} \eta_{e l} L A_{i l} \leq \xi_{q e}, \quad \forall q, e$.
Constraint (9) indicates that exhaust $e$ emission on segment $q$ should be less than the amount of given emissions on the corresponding segment.

$\left\{\begin{array}{l}T_{i s_{e q}}^{d}+h_{q} \leq T_{j s_{e q}}^{d}+\operatorname{big} M\left[\left(1-H_{i q}\right)+\left(1-H_{j q}\right)+\left(1-A_{i j q}\right)\right], \\ T_{i s_{l q}}^{a}+h_{q} \leq T_{j s_{l q}}^{a}+\operatorname{big} M\left[\left(1-H_{i q}\right)+\left(1-H_{j q}\right)+\left(1-A_{i j q}\right)\right], \\ T_{j s_{e q}}^{d}+h_{q} \leq T_{i s_{e q}}^{d}+\operatorname{big} M\left[\left(1-H_{i q}\right)+\left(1-H_{j q}\right)+\left(1-A_{j i q}\right)\right], \\ T_{j s_{l q}}^{a}+h_{q} \leq T_{i s_{l q}}^{a}+\operatorname{big} M\left[\left(1-H_{i q}\right)+\left(1-H_{j q}\right)+\left(1-A_{j i q}\right)\right], \\ A_{i j q}+A_{j i q}=H_{i q} H_{j q} .\end{array}\right.$

In constraint (10), a headway time is required between each pair of successive trains for the inbound trains due to signaling, safety, etc.

$\left\{\begin{array}{l}T_{i s_{e q}}^{d}+h_{q} \leq T_{j s_{e q}}^{d}+\operatorname{big} M\left[\left(1-H_{i q}\right)+\left(1-H_{j q}\right)+\left(1-C_{i j q}\right)\right], \\ T_{i s_{l q}}^{a}+h_{q} \leq T_{j s_{l q}}^{a}+\operatorname{big} M\left[\left(1-H_{i q}\right)+\left(1-H_{j q}\right)+\left(1-C_{i j q}\right)\right], \\ T_{j s_{e q}}^{d}+h_{q} \leq T_{i s_{e q}}^{d}+\operatorname{big} M\left[\left(1-H_{i q}\right)+\left(1-H_{j q}\right)+\left(1-C_{j i q}\right)\right], \\ T_{j s_{l q}}^{a}+h_{q} \leq T_{i s_{l q}}^{a}+\operatorname{big} M\left[\left(1-H_{i q}\right)+\left(1-H_{j q}\right)+\left(1-C_{j i q}\right)\right], \\ C_{i j q}+C_{j i q}=H_{i q} H_{j q} .\end{array}\right.$

In constraint (11), a headway time is required between each pair of successive trains for the outbound trains due to signaling, safety, etc.

$\left\{\begin{array}{l}T_{i s_{l q}}^{a} \leq T_{j s_{l q}}^{d}+\operatorname{big} M\left[\left(1-H_{i q}\right)+\left(1-H_{j q}\right)+\left(1-B_{i j q}\right)\right], \\ T_{j s_{l q}}^{a} \leq T_{i s_{e q}}^{d}+\operatorname{big} M\left[\left(1-H_{i q}\right)+\left(1-H_{j q}\right)+\left(1-B_{j i q}\right)\right], \\ B_{i j q}+B_{j i q}=H_{i q} H_{j q} .\end{array}\right.$

In constraint (12), a collision should be avoided between each pair of successive trains for the opposite trains.

\subsection{Multi-objective model}

A reasonable train timetable should consider both the operation cost and the trip time, which respectively represents the benefits of railway company and passengers. The following multi-objective optimization model which minimizes the operation cost and the total passenger-time:

$\min f(x)=\{E(x)+F(x), T(x)\}$.

Under the constraints (3)-(12), where $x=$ $\left(x_{1}, x_{2}, \ldots, x_{n}\right)$ is an $n$-dimensional decision vector containing all binary and continuous variables.

Note that if the train is viewed as a whole and exhaust $\mathrm{CO}_{2}$ emission is only considered, this model degenerates to the green scheduling model by Li et al. [15]. Moreover, if all the trains are electrified without any exhaust emissions, this model degenerates to the model proposed by Ghoseiri et al. [1]. 


\section{Model solution}

Fuzzy mathematical programing is an efficient approach to solve multi-objective optimization problems, which models each objective as a fuzzy set whose membership function represents the degree of satisfaction of the objective. The membership degree is usually assumed to rise linearly from zero (for the least satisfactory value) to one (for the most satisfactory value). Zimmermann first used the max-min operator to aggregate the fuzzy objectives for making a compromise decision [47]. However, it cannot guarantee a non-dominated solution and is not completely compensatory. To achieve full compensation between aggregated membership functions and to insure a non-dominated solution, we use the extended maxmin approach suggested by Lai and Hwang [48].

First, according to the single-objective optimization methods, it is easy to calculate the range for each objective. Here, we use $C_{\min }$ and $C_{\max }$ to denote the minimum and maximum operation costs, and use $T_{\min }$ and $T_{\max }$ to denote the minimum and maximum total passenger-times. Furthermore, we construct the membership function for cost objective

$\mu_{c}(x)=\left\{\begin{array}{cc}1, & \text { if } x<C_{\min }, \\ \frac{C_{\max }-x}{C_{\max }-C_{\min },} & \text { if } C_{\min } \leq x \leq C_{\max }, \\ 0, & \text { if } x>C_{\max },\end{array}\right.$

and the membership function for total passenger-time objective

$\mu_{t}(x)=\left\{\begin{array}{cc}1, & \text { if } x<T_{\min }, \\ \frac{T_{\max }-x}{T_{\max }-T_{\min },}, & \text { if } T_{\min } \leq x \leq T_{\max }, \\ 0, & \text { ifł } x>T_{\max } .\end{array}\right.$

Finally, we aggregate $\mu_{c}(x)$ and $\mu_{t}(x)$ using the augmented max-min operator and then formulate the following singleobjective optimization model

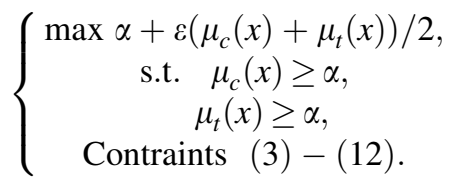

where $\alpha$ is an auxiliary variable which represents the overall satisfactory level of compromise (to be maximized) and $\varepsilon$ is a small positive number. Note that a non-dominated solution is always generated when $\alpha$ is maximized. The single-objective model (14) can be solved using the nonlinear optimization software such as LINGO, GAMS etc.

\section{Numerical example}

\subsection{Example description}

In this section, we present an example to illustrate the efficiency of the proposed model and solution method and make comparisons.

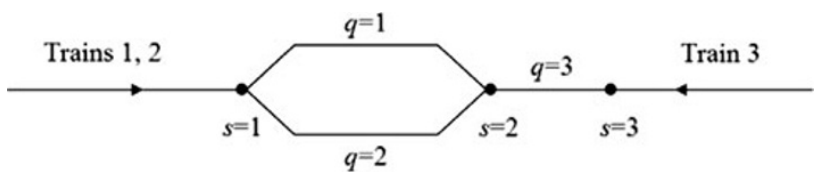

Fig. 1 A rail network containing three segments and three stations

In an example, we consider a small rail network which includes three segments and three stations (see Fig. 1). There are two outbound trains and one inbound train. All of them leave from their origin stations to station 2 and then arrive at their destination stations. Three types of locomotives are given and they are selected to constitute a train with carriages. We need to choose not only the optimal segment for outboard train to start its trip and for inboard train to complete its trip, but also the optimal assignment between locomotive and carriage. In addition, we need to determine each train's arrival and departure times at each station. The parameter values are shown in Table 1 .

Table 1 Parameter values in example

\begin{tabular}{|c|c|c|c|}
\hline Parameter & Value & Parameter & Value \\
\hline$N_{11}$ & 100 & $k_{0}^{l 1}$ & 2.28 \\
\hline$N_{21}$ & 100 & $k_{1}^{l 1}$ & 0.0293 \\
\hline$N_{31}$ & 200 & $k_{2}^{l 1}$ & 0.000178 \\
\hline$Y_{12}$ & 50 & $k_{0}^{l 2}$ & 2.40 \\
\hline$Y_{22}$ & 50 & $k_{1}^{l 2}$ & 0.0022 \\
\hline$Y_{32}$ & 50 & $k_{2}^{l 1}$ & 0.000391 \\
\hline$Z_{12}$ & 50 & $k_{0}^{l 3}$ & 0.86 \\
\hline$Z_{22}$ & 50 & $k_{1}^{l 3}$ & 0.0054 \\
\hline$Z_{32}$ & 50 & $k_{2}^{l 3}$ & 0.000218 \\
\hline$u \_v_{i q}$ & 140 & $l \_v_{i q}$ & 0 \\
\hline$\theta_{q}$ & 0 & $\lambda_{\mathrm{CO}_{2}}$ & 80 \\
\hline$Z_{22}$ & 50 & $k_{2}^{2}$ & 0.000145 \\
\hline$Z_{32}$ & 50 & $k_{0}^{3}$ & 1.61 \\
\hline$u \_v_{i q}$ & 140 & $k_{1}^{3}$ & 0.0040 \\
\hline$\theta_{q}$ & 0 & $k_{2}^{3}$ & 0.000187 \\
\hline$Z_{22}$ & 50 & $X_{i}^{O_{i}}$ & 0 \\
\hline$M_{l 1}$ & 135 & $\eta_{\mathrm{co}_{2}, l 3}$ & 0.0008 \\
\hline$M_{l 2}$ & 138 & $\eta_{\mathrm{NO}_{x}, l 1}$ & 0.000012 \\
\hline$M_{l 3}$ & 141 & $\eta_{\mathrm{NO}_{x}, l 2}$ & 0.000014 \\
\hline$M_{1}$ & 500 & $\eta_{\mathrm{NO}_{x}, l 3}$ & 0.000016 \\
\hline$M_{2}$ & 430 & $\eta_{\mathrm{PM}, l 1}$ & 0.0000012 \\
\hline$M_{3}$ & 460 & $\eta_{\mathrm{PM}, l 2}$ & 0.0000014 \\
\hline$r_{1}, r_{2}, r_{3}$ & $2 \times 10^{7}$ & $\eta_{\mathrm{PM}, l 3}$ & 0.0000016 \\
\hline$\eta_{\mathrm{co}_{2}, l 1}$ & 0.0006 & $h_{q}$ & 300 \\
\hline$\eta_{\mathrm{co}_{2}, l 2}$ & 0.0007 & $\Delta_{\mathrm{Co}_{2}}$ & 1 \\
\hline$X_{i}^{D_{i}}$ & 7,200 & $w_{i 2}$ & 200 \\
\hline $\operatorname{big} M$ & 100,000 & $g$ & 9.81 \\
\hline$c$ & 1 & & \\
\hline
\end{tabular}


5.2 Energy cost saving considering locomotive assignment without emission constraints

(1) Given locomotive assignment

In order to illustrate the efficiency of the proposed model, we first apply optimization software GAMS to solve the optimal timetable without considering locomotive assignment. In this example, locomotives $l 1, l 2, l 3$ are assigned to train 1, 2, and 3, respectively. The results are shown as follows:

(a) $H_{12}=H_{13}=1, d_{11}=300, a_{12}=3,071.01$, $d_{12}=3,791.01, a_{13}=7,200$,

(b) $H_{22}=H_{23}=1, d_{21}=0, a_{22}=2,721.64$, $d_{22}=3,441.64, a_{23}=6,900$,

(c) $H_{32}=H_{33}=1, d_{33}=0, a_{32}=4,229.74$, $d_{22}=4,949.74, a_{31}=7,200$,

(d) Energy cost is 824.25 and the total passenger-time is 783.33 .

(2) Locomotive assignment considered while the number of locomotives is limited.

Now, we consider the locomotive assignment, but the number of all types of locomotives is limited. Particularly, each locomotive is assigned as only one train in this example. The results are shown as follows:

(a) $L_{13}=1, H_{12}=H_{13}=1, d_{11}=300$,
$a_{12}=2,630.86, d_{12}=3,350.86, a_{13}=7,200$,
(b) $L_{22}=1, H_{22}=H_{23}=1, d_{21}=0$,
$a_{22}=2,317.24, d_{22}=3,037.24, a_{23}=6,900$,
(c) $L_{31}=1, H_{32}=H_{33}=1, d_{33}=0$,
$a_{32}=3,512.54, d_{22}=4,232.54, a_{31}=7,200$,

(d) Energy cost is 821.57 and the total passenger-time is 783.33 .

(3) Locomotive assignment considered while the number of locomotives is unlimited.

Furthermore, we consider the locomotive assignment, but the number of all types of locomotives is unlimited. The results are shown as follows:

(a) $L_{13}=1, H_{12}=H_{13}=1, d_{11}=308.15$,

$a_{12}=2,980.92, d_{12}=3,700.92, a_{13}=7,200$,

(b) $L_{23}=1, H_{22}=H_{23}=1, d_{21}=8.15$,

$a_{22}=2,072.14, d_{22}=2,792.14, a_{23}=6,900$,

(c) $L_{33}=1, H_{32}=H_{33}=1, d_{33}=0$,

$a_{32}=3,863.84, d_{22}=4,583.84, a_{31}=7,200$,

(d) Energy cost is 743.10 and the total passenger-time is 782.88 .

From the computation results, it can be seen that the energy cost is reduced by $33 \%$ and $9.85 \%$ effectively compared to the given locomotive assignment situation.
5.3 Energy cost saving considering locomotive assignment with emission constraints

Now, assume emissions of $\mathrm{NO}_{x}$ on segment $q 1, q 2, q 3$ are restricted to $0.002,0.003$, and 0.007 , while emissions of PM on segment $q 1, q 2, q 3$ are restricted to $0.0002,0.0004$, and 0.0007 . The energy cost variations with different locomotive assignments are discussed as below:

(1) Given locomotive assignment

Similar to Sect. 5.1 (1), the results are shown as follows:

(a) $H_{12}=H_{13}=1, d_{11}=300, a_{12}=3,154.27$, $d_{12}=3,874.27, a_{13}=7,200$,

(b) $H_{22}=H_{23}=1, d_{21}=0, a_{22}=2,380.71$, $d_{22}=3,100.71, a_{23}=6,576.43$,

(c) $H_{32}=H_{33}=1, d_{33}=0, a_{32}=3,497.14$, $d_{22}=4,217.14, a_{31}=7,200$,

(d) Then energy cost is 905.44 and the total passengertime is 774.35 .

(2) Given locomotive assignment while the number of locomotives is limited.

Similar to Sect. 5.1 (2), the results are shown as follows:

(a) $L_{13}=1, H_{12}=H_{13}=1, d_{11}=300$, $a_{12}=3,140.46, d_{12}=3,860.46, a_{13}=7,200$,

(b) $L_{22}=1, H_{22}=H_{23}=1, d_{21}=0$, $a_{22}=2,827.83, d_{22}=3,547.83, a_{23}=6,900$,

(c) $L_{31}=1, H_{32}=H_{33}=1, d_{33}=0$, $a_{32}=3,543.74, d_{22}=4,263.74, a_{31}=7,200$,

(d) Energy cost is 844.76 and the total passenger-time is 783.33.

(3) Locomotive assignment considered while the number of locomotives is unlimited.

Similar to Sect. 5.1 (3), the results are shown as follows:

(a) $L_{13}=1, H_{11}=H_{13}=1, d_{11}=15.22$, $a_{12}=2,371.84, d_{12}=3,091.84, a_{13}=7,195.63$,

(b) $L_{23}=1, H_{22}=H_{23}=1, d_{21}=7.30$, $a_{22}=2,068.80, d_{22}=2,788.80, a_{23}=6,895.63$,

(c) $L_{33}=1, H_{32}=H_{33}=1, d_{33}=15.63$, $a_{32}=3,861.97, d_{22}=4,581.97, a_{31}=7,200$,

(d) Energy cost is 773.41 and the total passenger-time is 789.93.

From the computation results, it can be seen that the energy cost is reduced by $6.7 \%$ and $14.58 \%$ effectively compared to the given locomotive assignment situation.

Surprisingly, the reduction percent of energy cost saving with segment emission restriction is better than that of without segment emission restriction. Maybe, it is concerned with the amount of segment emissions and optimal software computation capability. 


\subsection{Comprehensive results analysis}

Finally, we apply fuzzy mathematical programing to solve this multi-objective optimization problem. First, the minimum and maximum energy and emission operation costs are calculated to be 844.96 and 1135.40 , and the minimum and maximum total passenger-times are 622.86 and 783.33. Furthermore, we solve the multi-objective optimization model (13). The results are concluded as follows:

(a) $L_{12}=1, H_{12}=H_{13}=1, d_{11}=244.38$, $a_{12}=2,743.69, d_{12}=3,463.69, a_{13}=6,900$,

(b) $L_{21}=1, H_{22}=H_{23}=1, d_{21}=1,056.93$, $a_{22}=3,340.31, d_{22}=4,060.31, a_{23}=7,200$,

(c) $L_{33}=1, H_{32}=H_{33}=1, d_{33}=500.73$, $a_{32}=3,329.30, d_{22}=4,049.30, a_{31}=6,106.44$,

(d) Energy cost is 968.70 , emission cost is -43.94 , and total passenger-time is 666.95 .

Although the energy cost is increased, the total operation cost is diminished due to the emission allowance change. Meanwhile, compared to single energy cost optimization model in Sect. 5.2 (2), total passenger-time is reduced by $14.86 \%$. It seems that this fuzzy multi-objective optimization model can derive more reasonable results.

Furthermore, if the numerical example is enlarged to include more trains and segments like the model in Ref. [1], a similarity exists that the computation time is more sensitive to the number of trains than to the number of segments in the network.

\section{Conclusion}

We put forward an energy saving train-scheduling multiobjective optimization model, which minimizes the energy cost and exhausts emission and total trip time by considering the locomotive assignment and segment emission constraints. The fuzzy multi-objective optimization approach is employed to get the non-dominated timetable which has equal satisfaction degree for passenger-time and cost. Finally, a numerical example was presented and compared to demonstrate that the proposed model can reduce the energy consumption significantly compared with the existing models and trade off operation cost against trip time.

Acknowledgments This study was supported by the National Natural Science Foundation of China (No. 71101007), the National High Technology Research and Development Program of China (No. 2011AA110502), State Key Laboratory of Rail Traffic Control and Safety of Beijing Jiaotong University Program (RCS2010ZZ001).
Open Access This article is distributed under the terms of the Creative Commons Attribution License which permits any use, distribution, and reproduction in any medium, provided the original author(s) and the source are credited.

\section{References}

1. Ghoseiri K, Szidarovszky F, Asgharpour MJ (2004) A multiobjective train scheduling model and solution. Transp Res B 38:927-952

2. Bussieck MR, Winter T, Zimmermann UT (1997) Discrete optimization in public rail transport. Math Program 79:415-444

3. Higgins A, Kozan E, Ferreira L (1996) Optimal scheduling of trains on a single line track. Transp Res B 30(2):147-161

4. Lindner $\mathrm{T}$ (2000) Train schedule optimization in public rail transport. Dissertation, Technische Universitat Braunschweig

5. Frank O (1966) Two-way traffic on a single line of railway. Oper Res 14(5):801-811

6. Petersen ER, Taylor AJ (1982) A structured model for rail line simulation and optimization. Transp Sci 16(2):192-206

7. Chiang T, Hau H, Chiang H et al (1998) Knowledge-based system for railway scheduling. Data Knowl Eng 27(3):289-312

8. Zweben M, Davis E, Daun E et al (1993) Scheduling and rescheduling with iterative repair. IEEE Trans Syst Man Cybern 23(6): 1588-1596

9. Amit I, Goldfard D (1971) The timetable problem for railways. Dev Oper Res 2:379-387

10. Szpigel B (1973) Optimal train scheduling on a single track railway. Oper Res 72:343-352

11. Sauder RL, Westerman WM (1983) Computer aided train dispatching: decision support through optimization. Interfaces 13(6):24-37

12. Jovanovic D, Harker PT (1991) Tactical scheduling of rail operations: the SCAN I system. Transp Sci 25(1):46-64

13. Carey M (1994) A model and strategy for train pathing with choice of lines platforms and routes. Transp Res B 28(4):333-353

14. Carey M (1994) Extending a train pathing model from one-way to two-way track. Transp Res B 28(5):395-400

15. Li X, Wang D, Li K et al (2013) A green train scheduling model and fuzzy multi-objective optimization algorithm. Appl Math Model 37(4):2063-2073

16. Cordeau JF, Toth P, Vigo D (1998) A survey of optimization models for train routing and scheduling. Transp Sci 32(4):380-404

17. Miller AR, Peters J, Smith BE, Velev OA (2006) Analysis of fuelcell hybrid locomotives. J Power Sources 157:855-861

18. Stodolsky F (2002) Railroad and locomotive technology roadmap. Center for Transportation Research, Argonne National Laboratory, Lemont

19. Smith ME (1987) Economics of reducing train resistance. In: Proceedings Railroad Energy Technology Conference II, Association of American Railroad, Chicago, pp 269-305

20. Engdahl R, Gielow RL, Paul JC (1987) Train resistance-aerodynamics volume I of II intermodal car application. In: Proceedings of Railroad Energy Technology Conference II, Association of American Railroad, Washington, DC, pp 225-242

21. Lai Y-C, Barkan CPL, Onal H (2008) Optimizing the aerodynamic efficiency of intermodal freight trains. Transp Res E 44:820-834

22. Cheng Y-H, Yang AS, Tsao H-L (2006) Study on rolling stock maintenance strategy and spares parts management. In: 7th World Congress on Railway Research, Montreal 
23. Yun WY, Luis F (2003) Prediction of the demand of the railway sleepers: a simulation model for replacement strategies. Int J Prod Econ 81-82:589-595

24. Asnis A, Dmitruk A, Osmolovski N (1985) Using the maximum principle to solve the problem of energy-optimal control of the motion of the trains. Zh Vychisl Mat Mat Fiz 25(11):1644-1656

25. Benjamin BR, Milroy BI, Pudney P (1989) Energy-efficient operation of long-haul trains. In: Proceedings of the Fourth International Heavy Haul Railway Conference, Institution of Engineers, Brisbane, 11-15 Sept 1989, pp 369-372

26. Howlett PG, Pudney PJ (1995) Energy-efficient train control, advances in industrial control. Springer-Verlag, London

27. Liu RR, Golovitcher IM (2003) Energy-efficient operation of rail vehicles. Transp Res A 37:917-932

28. Golshani F, Thomas T (1981) Optimal distribution of slack-time in schedule design. Traffic Eng Control 22(8-9):490-492

29. Hee-Soo H (1998) Control strategy for optimal compromise between trip time and energy consumption in a high-speed railway. IEEE Trans Syst Man Cybern A (Syst Hum) 28(6):791-802

30. Sicre C, Cucala P, Fernández A et al (2010) A method to optimise train energy consumption combining manual energy efficient driving and scheduling. In: The 7th High World Congress on High Speed Rail, Beijing

31. Hill N, Kollamthodi S, Hazeldine T et al (2005) Diesel Rail Study Final Report: technical and operational measures to improve the emissions performance of diesel rail. AEA Technology Environment, Oxfordshire

32. Chan M, Jackson MD (2007) Evaluation of the advanced locomotive emission control system (ALECS). TIAX LLC, Cupertino, pp 19-31

33. Jorgensen MW, Sorenson SC (1997) Estimating emissions from railway traffic. Dissertation, Denmark Technical University of Denmark, pp 11-93

34. Kean AJ, Sawyer RF, Harley RA (2000) A fuel-based assessment of off-road diesel engine emissions. J Air Waste Manag Assoc 50:1929-1939

35. Hobson M, Smith A (2001) Rail emission model, strategic rail authority. AEA Technology Inc., Carlsbad

36. Lindgreen E, Sorenson SC (2004) Simulation of energy consumption and emissions from rail traffic. Dissertation, Denmark Technical University of Denmark, pp 11-70
37. Southeastern States Air Resource Managers, Inc. (2004) Development of railroad emission inventory methodologies. Southeastern States Air Resource Managers, Inc., Forest Park, pp 1-36

38. Dincer F, Elbir T (2007) Estimating national exhaust emissions from railway vehicles in Turkey. Sci Total Environ 374(1):27-134

39. Gould G, Niemeier D (2009) A review of regional locomotive emission modeling and the constraints posed by activity data. Transport Res Rec 2117:24-32

40. Gould G, Niemeie DA (2011) Spatial assignment of emissions using a new locomotive emissions model. Environ Sci Technol 45(13):5846-5852

41. Holland M, Hunt A, Hurley F et al (2005) Methodology for the costbenefit analysis for café, vol 1: overview of methodology. http:// ec.europa.eu/environment/archives/cafe/pdf/cba_methodology_ vol1.pdf. Accessed 28 Feb 2005

42. Ballanti D (2005) Air quality impact of recreational rail service SANTA CRUA_APTOS Recreational Rail Project, pp 1-9

43. Mahmood A, Pham C (2007) Health risk assessment for the four commerce railyards. http://www.arb.ca.gov/railyard/hra/4com_hra. pdf. Accessed 30 Oct 2007

44. Sangkapichai M, Saphores JD, Ritchie S et al (2009) An analysis of PM and NOx Train Emissions in the Alameda Corridor. Dissertation, Department of Civil \& Environmental Engineering University of California, pp 1-15

45. Lindhjem CE, Friesen RA (2009) Assessment of available tools and methodologies to quantify regional and project level air quality effects for freight railroads. ENVIRON International Corporation, Novato, pp 1-21

46. Hay WW (1982) Railroad engineering, 2nd edn. Wiley, New York

47. Zimmermann HJ (1978) Fuzzy programming and linear programming with several objective functions. Fuzzy Set Syst 1(1):45-55

48. Lai YJ, Hwang CL (1994) Fuzzy multiple objective decision making: methods and applications. In: Lecture Notes in Economics and Mathematical Systems. Springer-Verlag, New York 